\title{
GASEOUS NITROGEN HEAT EXCHANGER
}

D-Zero Engineering Note: 3740.510-EN-174

C.H. Kurita

$\begin{array}{lll}\text { August } \quad 19, & 1988\end{array}$

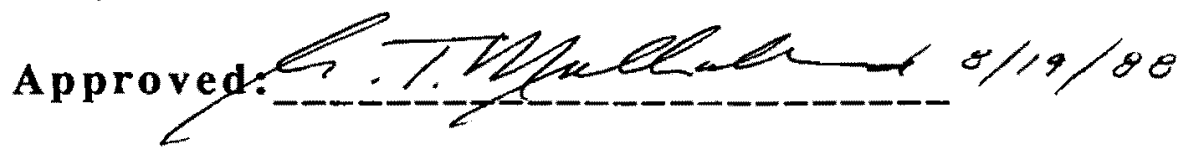


A heat exchanger is necessary to warm the gaseous nitrogen from the nitrogen dewar from $77 \mathrm{~K}$ to ambient temperature for use in the D-Zero Building. The original proposal would use an ambient air vaporizer, but further investigation led to the consideration and evaluation of other possibilities and a different final system. The vaporizer must be able to handle a flow rate of $1200 \mathrm{scfh}$ at $30 \mathrm{psig}$ on a continuous basis subject to local weather conditions.

Upon consulting with a representative from Thermax Incorporated, So. Dartmouth, Massachusetts, four different heat exchanging systems were proposed. Their advantages and disadvantages are stated as follows.

Option \#1: Single large ambient air vaporizer sized for approximately three times the expected flow

- use of super-gap modules allows for a longer period before ice bridging between elements occurs

\section{Advantages}

- in the event of overdrawing, all liquid is vaporized

- low pressure drop

\section{Disadvantages}

- must periodically knock off ice

- final gas temperature can only approach ambient

Option \#2: Electric heater (only)

- flow rate is small enough that an electric heater can be used

\section{Advantages}

- gas is fully heated to ambient temperature (or above) as required

\section{Disadvantages}

- greater potential for operational problems 
- may see liquid if overdrawing occurs

- high pressure drop

Option\#3: Electric heater/Ice-rack hybrid

- placing an ice-rack before the heater lightens the load on the heater by acting as a pre-heater

\section{Advantages}

- gas is fully heated to ambient temperature (or above) as required

- in the event of overdrawing, ice-rack will vaporize the liquid

\section{Disadvantages}

- greater potential for operational problems

- high pressure drop

Option \#4: Two smaller ambient air vaporizers in parallel with an electrically actuated diverted valve

- use of super-gap modules extends the period before ice-over occurs, and switching between the modules allows for one unit to defrost while the other is in use

\section{Advantages}

- in the event of overdrawing, all liquid is vaporized

- low pressure drop

- simple valve control through PLC

Disadvantages

- must periodically knock ice off in very cold weather

- final gas temperature can only approach ambient 
After weighing the advantages and disadvantages of each option, it was decided that Option \#4 would be best suited for the intended application. The system selected includes two Thermax super-gap ambient air vaporizers (\#TF0410-HF-SG) and a Worcester Controls 3way cryogenic ball valve (\#C416-PMSE-V1) with a NEMA IV $110 \mathrm{~V}$ actuator (\#1275W).

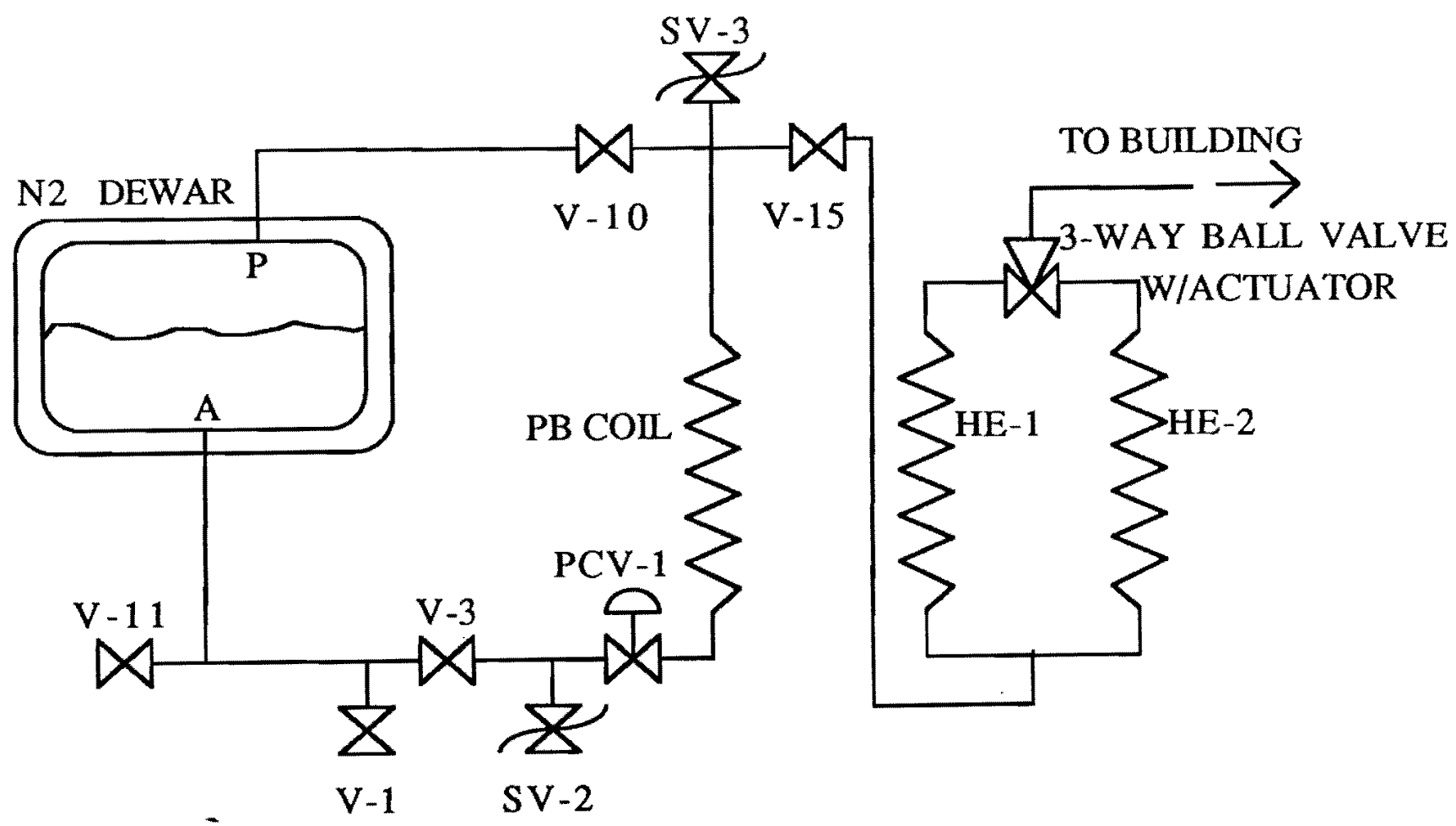
A $\quad$ BOTTTOM FILL/PRESS. BUILD LINE
$P \quad$ PRESSURE BUILD RETURN LINE
V-1 BOTTOM FILL VALVE
$\mathrm{V}-3$
$\mathrm{V}-10$
$\mathrm{V}-11$
$\mathrm{V}-15$
$S V-2$
$S V-3$
PCV-1
HE-1
HE-2 PRESSURE BUILD LIQUID SHUT-OFF VALVE VAPOR RETURN VALVE AUXILIARY LIQUID WITHDRAWL VALVE GASEOUS $\mathrm{N}_{2}$ WITHDRAWL VALVE PRESSURE BUILD LIQUID SAFETY VALVE PRESSURE BUILD VAPOR SAFETY VALVE PRESSURE BUILD CONTROL VALVE THERMAX AMBIENT AIR VAPORIZER (1) THERMAX AMBIENT AIR VAPORIZER (2) PB COIL PRESSURE BUILDING COIL 


\title{
GASEOUS NITROGEN
}

\section{HEAT EXCHANGER}

D-Zero Engineering Note: 3740.510-EN-174

\author{
C.H. Kurita
}

August 19, 1988

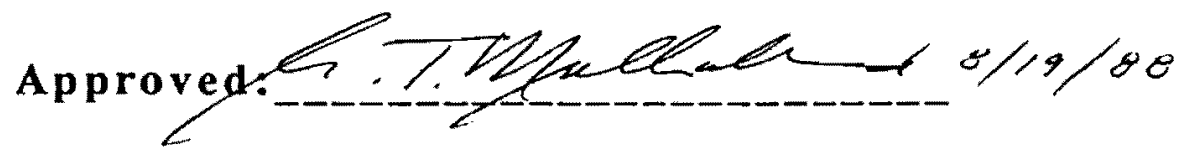


A heat exchanger is necessary to warm the gaseous nitrogen from the nitrogen dewar from $77 \mathrm{~K}$ to ambient temperature for use in the D-Zero Building. The original proposal would use an ambient air vaporizer, but further investigation led to the consideration and evaluation of other possibilities and a different final system. The vaporizer must be able to handle a flow rate of $1200 \mathrm{scfh}$ at $30 \mathrm{psig}$ on a continuous basis subject to local weather conditions.

Upon consulting with a representative from Thermax Incorporated, So. Dartmouth, Massachusetts, four different heat exchanging systems were proposed. Their advantages and disadvantages are stated as follows.

Option \#1: Single large ambient air vaporizer sized for approximately three times the expected flow

- use of super-gap modules allows for a longer period before ice bridging between elements occurs

\section{Advantages}

- in the event of overdrawing, all liquid is vaporized

- low pressure drop

Disadvantages

- must periodically knock off ice

- final gas temperature can only approach ambient

Option \#2: Electric heater (only)

- flow rate is small enough that an electric heater can be used

\section{Advantages}

- gas is fully heated to ambient temperature (or above) as required

Disadvantages

- greater potential for operational problems 
- may see liquid if overdrawing occurs

- high pressure drop

Option\#3: Electric heater/Ice-rack hybrid

- placing an ice-rack before the heater lightens the load on the heater by acting as a pre-heater

\section{Advantages}

- gas is fully heated to ambient temperature (or above) as required

- in the event of overdrawing, ice-rack will vaporize the liquid

\section{Disadvantages}

- greater potential for operational problems

- high pressure drop

Option \#4: Two smaller ambient air vaporizers in parallel with an electrically actuated diverted valve

- use of super-gap modules extends the period before ice-over occurs, and switching between the modules allows for one unit to defrost while the other is in use

\section{Advantages}

- in the event of overdrawing, all liquid is vaporized

- low pressure drop

- simple valve control through PLC

\section{Disadvantages}

- must periodically knock ice off in very cold weather

- final gas temperature can only approach ambient 
After weighing the advantages and disadvantages of each option, it was decided that Option \#4 would be best suited for the intended application. The system selected includes two Thermax super-gap ambient air vaporizers (\#TF0410-HF-SG) and a Worcester Controls 3way cryogenic ball valve (\#C416-PMSE-V1) with a NEMA IV $110 \mathrm{~V}$ actuator (\#1275W).

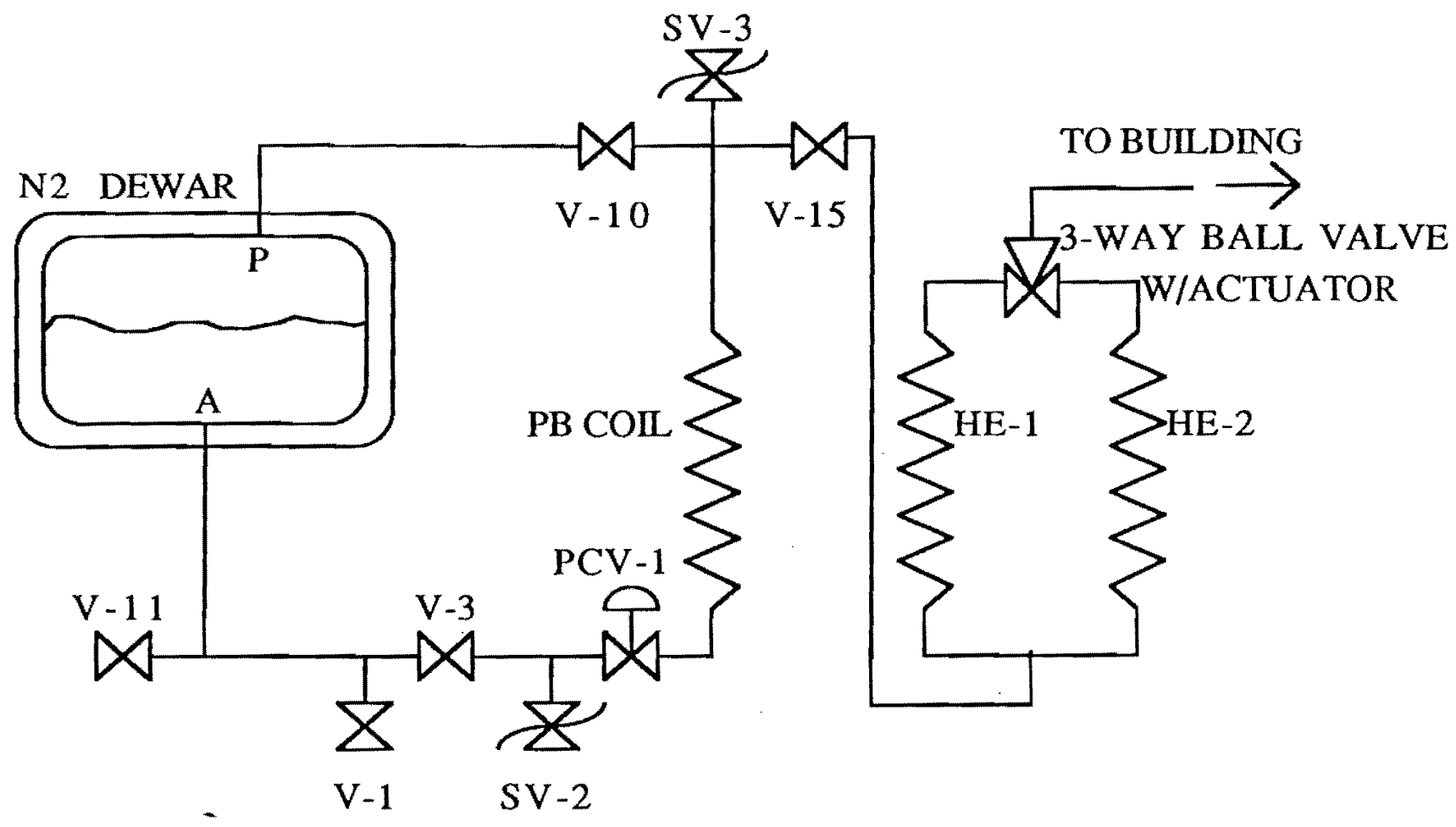
A
BOTTTOM FILL/PRESS. BUILD LINE
$P \quad$ PRESSURE BULLD RETURN LINE
V-1 BOTTOM FILL VALVE
$V-3$
$\mathrm{V}-10$
$\mathrm{V}-11$
$\mathrm{V}-15$
SV-2
$S V-3$
PCV-1
PRESSURE BUILD LIQUID SHUT-OFF VALVE
VAPOR RETURN VALVE
AUXILIARY LIQUID WITHDRAWL VALVE
GASEOUS $N_{2}$ WITHDRAWL VALVE
PRESSURE BUILD LIQUID SAFETY VALVE
HE-1
HE-2
PRESSURE BUILD VAPOR SAFETY VALVE
PRESSURE BUILD CONTROL VALVE
THERMAX AMBIENT AIR VAPORIZER (1)
THERMAX AMBIENT AIR VAPORIZER (2)
PB COIL PRESSURE BUILDING COIL 